\title{
Quality Management System for Contemporary Public Administration: A case study of e-Governance
}

\author{
Dr. T. G. K. Vasista \\ King Saud University \\ PO Box 2454, Riyadh 11451, Saudi Arabia \\ Tel: 00966564414740 E-mail: gtatapudi@ksu.edu.sa
}

Received:November 18, 2012 Accepted:December 14, 2012 DOI:10.5296/jpag.v2i4.2798

\begin{abstract}
The quality movement in Public Administration is a part of reform and modernisation efforts aimed at replacing the bureaucratic model by a more citizen-oriented paradigm. Governments are considered organisations that are capable enough to quickly adopt new technologies to engage and serve constituents. While e-Government embraces the use of information and communication technologies in public administration (combined with organisational change) to improve public services, e-governance on the other hand focuses on the idea of creating a government that is closer to the citizens it serves and more open to their participation at several levels. Research is needed on how the dynamic, competitive web culture affects citizen (and other user) demands for electronic service quality in the process of achieving customer satisfaction. The main theoretical argument behind this paper is that governments in the process of establishing quality management system in public administration should focus on working towards e-governance, which is citizen centric so as to create right organisational environment to achieve the effectiveness, efficiency and equity.
\end{abstract}

Keywords: e-Governance, Good Governance, Public Administration Quality Management, Total Quality Management 


\section{Introduction}

Governments are considered organisations that are capable enough to quickly adopt new technologies to engage and serve constituents. Web sites act as tools for governments for communicating and providing services to their constituents. A recent International City/County Management survey of more than 4000 local governments in United States found that $85 \%$ of the municipalities are responding through their active web sites. Many policymakers, e-government service providers and scholars argue that the World Wide Web offers unprecedented potential for governments to improve efficiency, effectiveness and public trust. Research is needed on how the dynamic, competitive web culture affects citizen (and other user) demands for electronic service quality. As web site content and its use are continuously increasing, governments must regularly monitor and enhance the quality of their sites to attract and satisfy users (Scott 2005).

\section{Research Questions}

At this juncture, four important research questions are at hand for which the answers are required to be elicited. They are:

1) Is the government, as a whole, well-run?

2) What are the important public service areas to be focused from the perspective of establishing an effective quality management system?

3) Does the government have the management capacity required to deliver public services?

4) What are the measures of public management and public services?

Development of quality management system in public administration has been at the centre of attention for the governments promoting e-government and e-governance through web sites since the beginning of its operation (Zurga 2008).

For answering the above questions, an attempt to bring the literature findings for satisfying the requirements mentioned in the knowledge of the definition of quality in public administration provided by Loffler (2001:3) for the duration from 1980 to present has been considered as a basis.

\section{Building Theoretical Basis}

According to Loffler (2001), defining quality in public administration should focus on achieving maximum customer satisfaction. Governments are aware and recognized that the quality is reflected through the customer satisfaction at an adequate cost. Customer Satisfaction is imperative for all public organisations from the perspective of growing awareness on public and consumer rights with public services (Ferreiera and Diniz 2004).

According to Loffler (2001), the quality management system should focus on the Total Quality Management. Total Quality Management (TQM) in the context of public administration can be defined as "a systematic approach for a high level strategy that works horizontally across different government, public and private departments for the purpose of achieving and increasing customer satisfaction permanently or consistently (Ferreiera and 
Diniz 2004) through continuous process improvement methodology (Kanjii 2002). TQM refers to a set of principles, tools and management processes to improve, modernize and render public service quality more effectively (West et al. 1993) by means of bringing organisational change, organisational culture with leadership transformation and promotes representative leadership (Ehrenberg and Stupark 1994).

According to Loffler (2001), the parameter of quality management system is the 'customer expectations'. Quality management has been regarded as essential to cope up with economy, efficiency, effectiveness and equity to respond to the rise citizen/customer satisfaction (Moura e Sa 2009, Moura e Sa 2011).

According to Loffler (2001), Continuous Process Improvement (CPI) becomes a management instrument of Total Quality Management. Throughout the continuous improvement process, quality tools are essential to identify customer needs and expectations (Moura e Sa 2009). To measure the perception of public service experience and expectations, the same three variables viz., effectiveness, efficiency and equity will be used. This allows focusing on gap analysis approach (AlSudairi, 2012) through comparing expected service quality with experienced services ( Naz 2009) at the finer grained level.

According to Loffler (2001), the technological change should support the service economy in the globalised markets. Globally, there has been extensive restructuring of existing firms is happening for reorganizing their activities around their core competencies. Outsourcing of wide range of service-related activities has been becoming a choice with the strong growth in Internet/ICT related service providers (Barker et al. 2008). These developments have been brought along with lightly regulated product markets, efficient market for corporate control, strong supply of venture capital and a climate that is conducive to risk-taking and entrepreneurship. This is because services are considered as a diverse group of economic activities that include high technology and knowledge intensive sub-sectors (OECD-STI 2000). Service sector includes a wide range of economic activities that are essential for the efficient operation of an economy and a source of competitive advantage. Service constitutes the vast majority of the global economy covering about two-thirds of world Gross Domestic Product (GDP) and foreign direct investment (FDI). For example, from 1974 to 2004, service share of world GDP grew from 53\% to 68\%. They became important value addition to manufacturing industry. Governments can enhance competitiveness of their economies both by supporting development of a competitive domestic service industry and by ensuring access to services in the global market. This infers and suggests that it is becoming essential for the government leaders to focus their activities towards services sector when devising plans to foster innovation, promote economic growth and to create jobs (IBM Governmental Programs 2006). Service quality in public administration requires considering both objective and subjective aspects of service and requires considering business administration techniques to measure service quality (Wiki-Service Quality)

According to Loffler (2001), the perspective on quality should not be limited to provider alone. It should be extended to supplier, customer and competitor too. There is a general agreement that the public sector is complex and involves a variety of stakeholders spanning 
with financial, social and political dimensions. This is because the basic definition of stake holder says "a stake holder in an organsiation is any group or individual who can affect or is affected by the achievements of the oraganisation's objective (Freeman, 1984, p. 25)" (Rowley 2011).

According to Loffler (2001), the quality management system model for organisations should support self-assessment capabilities. European Foundation for Quality Management (EFQM) model suggests Self-assessment is one of the essential elements in the organisational quality assessment others being, benchmarking, external review and quality awards (Nabitz, Klazinga and Walburg, 2000).

According to Loffler (2001), the nature of the time dimension should be considered dynamic as against static. This is because as the passage of time, the company as well as the competitors' condition will certainly change. Therefore benchmarking process should not remain static. A competitive advantage, generally can be gained if a company can address not only what the customer values most but also performing better than competitors in terms of quality, cost and timeliness. Customer needs does not follow a constant phenomenon. They change over time and hence dynamic benchmarking is essential to strive for continuous service quality improvement (Raharjo, Brombacher, Chai and Bergman 2008).

\section{Answering Research Questions}

This brings us to provide answers for the research questions.

1) Is the government, as a whole, well-run?

Answer: This requires focusing on building assessment framework for the quality of government-wide management system. The framework should provide key functional areas of public services to be focused and should suggest important measures of public management. In other words, it is a framework with the capability of public management to produce public services as outputs aligned with the social and economic concerns sought by the government (Schacter 2008).

2) What are the important areas to be focused from the perspective of establishing an effective quality management system?

Answer: There are two important broad areas of to be focused while establishing an effective quality management system. They are: (i) Public Service and (ii) Public Management (Schacter 2008).

3) Does the government have the management capacity required to deliver public services?

Answer: The role of Public Management is to provide direction and coordinate activities, structures, processes, procedure, rules, norms and incentives established within the public service that facilitate, monitor and control the outputs of the public sector. Outputs are delivered with a view to realizing outcomes established by the government. The role of public service is to respond to directions of the public management from the government on social and economic outcomes in the form of providing and delivering public services. The 
public service supports the realization of these outcomes proposed through the design and implementation programs. The public service must act in accordance with the laws and regulations that govern it and in a manner consistent with core values and beliefs of citizen expectations. The government must be in a position to self-assess the capacity of public management in terms of how effectively and efficiently it is delivering public services by reflecting the equity.

4) What are the measures of public management and public service?

There are three important measures of public management. They are: (i) Efficiency (ii) Effectiveness and (iii) Equity.

The key broad functional measures to be focused in public service (Loffler 2001) are: (i) Customer Satisfaction (ii) Customer Expectations (iii) Electronic Service Quality (iv) Dynamic Benchmarking Capability (v) Self-Quality Assessment Capability and (vi) Total Quality Management.

\section{Role of E-Governance in Quality Management}

A key measure of good governance however is through the public sector that is in charge of delivering transparent and quality services. If governance in an economy is weak, then there is a major reduction in the quality of public services. Service delivery was also the central theme of the world development report. The main reason for emphasizing the service delivery was that the public sector has been slow and unresponsive to the citizen needs in the modern times. According to the International Bank for reconstruction and development/World Bank (2005) public service delivery has been inconsistent with citizen preferences and considered feeble in developing countries. According to Economist Intelligence Unit survey, majority believe that IT's role will be to predominantly improve quality of services in the public sector worldwide. So the quality of public management and the quality of public services are the two important quality considerations (Naz 2009).

E-governance can address number of principal aims of quality such as efficiency, effectiveness and equity with customer centricity. Services need to be effective in delivering a level of performance that meets customer needs or expectations.

Effectiveness typically refers to doing the right things with measures such as: customer satisfaction, service quality, speed, timing and citizen/customer interactivity. A Service is said to be effective when its outcomes or accomplishments are of value to its customer and hence customer centric approach gained importance in good governance (Naz 2009). It is the degree to which firm meets goals (Lovelock and Wirtz 2007).

Efficiency is the difference between input and output expressed as percentage. It involves comparison to a standard and usually time-based (for example how long employee takes to perform a specific critical task) (Lovelock and Wirtz 2007).

Equity refers to the need to provide services to all citizens or equal access to those who require the specific services provided. In general, public organisations focus more on equity and effectiveness and less on efficiency; and profit based organisations focus more on 
efficiency, less on effectiveness and not all on equity (Naz 2009).

E-Governance will be able to streamline bureaucratic procedures to make operations more efficient. Adoption of IT in service organisations can bring competitive advantage including the creation of entry barriers, enhancement of productivity and increased revenue generation from new services. E-Governance can improve service delivery (Naz 2009).

Customer Satisfaction and Customer Expectations: The first and probably the most widespread conceptualization refer to customer satisfaction. Indeed, the term e-governance is not only used here as being synonymous of e-government but also synonymous with satisfying citizen/customer by means of delivering the services through the Internet. Generally, this is the view of promoters of new public management who see in the ICT's significant contribution to improving service delivery to achieve customer satisfaction. From this conceptualization, the interface with the citizens is improved by the main unit of analysis i.e. the government or rather administration with the help of using ICT (Misuraca 2007). But the essential difference of e-Governance with e-Government here is the provision of an active experience to the citizen or customer as against the passive experience in the process of dealing with public services. It means providing the ability to interface with public management if needed for the purpose of enabling the citizens or customers in making better decisions and choices about their RFP/Contract. It is because e-governance involves multiple channels for accessing government, multiple styles of leadership, multiple methods of transacting business and multiple systems for organizing and delivering information and services. The value of good governance lies in allowing this kind of choice based decision making to citizens/customer as customers expects and feel more satisfied when they are allowed to make their own choices and styles of receiving their public services from the given set of government trends and patterns of providing public services (Infocomm Development Authority of Singapore, p. 11). Citizens in all nations always expect creation and delivery of high quality services from their respective government (Agarwal, Shah and Wadhwa).

Electronic Service Quality: As governments are viewed as public service providers, a high quality service will ensure a high level of user citizen's satisfaction and acceptance of e-governance. Measuring service quality is very important as most governments regard improvement of the quality of public services as an objective of e-government programmes. The quality of e-government services is often assessed as citizen satisfaction, measured through interviews or online questionnaires. Frequent surveys of citizen satisfaction are of particular importance in e-government, as customer's expectations and habits are evolving rapidly in a changing service environment. Results from these surveys may be used to identify improvements that meet user needs by making services more accessible and effective. Results may be used to update service quality standards (OECD and Dubai School of Government). Various researchers have identified several dimensions of e-service quality. But there is lacking of consistency in those proposals (Agarwal 2007). Majority of research works have either focused on the quantitative analysis based research leaving to establish theoretical basis on how these electronic service dimensions are selected. Discrepancy or Gap method based approach to find the Electronic Service Quality factors as instrument of quality 
measurement is suggested as a preferable approach (Agarwal 2007; AlSudairi 2012). An effective Electronic Service Quality Strategy for achieving customer satisfaction with a rationale for selecting the electronic service quality dimensions has been given by AlSudairi (2012).

Self-Quality Assessment: The EFQM Excellence Model that was introduced in 1992 for self-assessment of quality in organisations and the Common Assessment Framework designed for self-assessment in the public sector was found deficient to evaluate e-governance quality as neither takes into account the difficulty of measuring the benefits of ICTs. However the report from OECD and Dubai School of Government (2007, p. 13 \& 14) provides various tools and practices in e-government measurement and evaluation that include: MAREVA by a French Electronic Administration Department Agency; The METER tool kit that provides evaluation framework linking ICT policy, strategies, initiative and action with proposed identifiable and measurable indicators for each of the mentioned levels; Norwegian Approach to evaluating performance at the programme level; Korea's e-government evaluation methodology and practice; Canada's Common Measurement Tool CMT- and benchmarking practices (OECD and Dubai School of Government 2007, p. 91).

Dynamic Bench Marking Capability: While conceptualizing the e-Governance concept, it is required to be understood that eGovernance can range from naïve and promotional views to simplistic and un-ambitious ideas of using ICTs for enhancing service delivery as a dynamic process of enhancing interactions between various actors (citizens/consumers, administrators, business people and civil society). This dynamic process consists of several stages including raising awareness about the potential of ICTs for community development; encouraging basic use of ICTs; providing specific products and content to meet local demands. This is a challenging situation because it involves the need to be able to adjust to the pace of increasing community needs. Political decision makers are affected by these challenges because they must set up legal and regulatory frameworks that create the optimum conditions for equal access and appropriation of ICTs within and by the communities. The research effort of Raharjo et al. (2008) demonstrates how dynamics of competitors and the dynamics of customer preferences can be incorporated into a Quality Function Deployment (QFD) analysis. The ultimate goal of analyzing the dynamics of these two factors as well as their interaction is to come out with better strategies with respect to the constantly changing market, particularly using QFD for dealing with dynamic market (Raharjo et al, 2008).

Total Quality Management: It seems essential to exploit the synergies of Total Quality Management TQM) and e-Government in order to bring the institutional change, enhance sustainability and produce long-term results. Moura e Sa (2011) investigated the potential link between e-Government implementation and TQM in the local government context in Portugal. The findings reveal that municipalities are considered more matured where e-Government initiatives are found with TQM implementation. However certification, one of the essential elements of Quality proposed of EFQM model apparently does not have an impact on e-Government adoption. Total Quality Management is a set of principles and tools that aim to mobilize the whole organisation in the pursuit of highest level of customer satisfaction at the lowest cost. In order to achieve this, people involvement and continuous 
process improvement need to be practiced on a daily basis. Egoless attitude with service orientation by strong leadership, teamwork and education \& training with active listening will lead to continuous improvement culture (Moura e Sa 2011).

\section{Building Framework}

While establishing a quality management system for effective public administration, the two important considerations made are: (i) clearly understand how e-governance can be distinguished from e-government and (ii) build a framework that describes the challenges and measures in the quality management system.

(i) This difference is explicitly mentioned as: 'e-government is the conceptualization of the application of ICT by the state for the production of its services' and 'e-governance is understood as the way the state acts (as a designer) to create favourable framework conditions for the general development of an information society based on e-media - either in cooperation with or without business and society (Aichholzer 2001). This understanding on the difference of e-government and e-governance can be challenged with the support of definition given for Governance and e-Governance by the UNESCO that e-governance must consider the involvement of citizens, articulation of their interests and exercise of their legal right and obligations ( $11^{\text {th }}$ India Report). However the decision making regarding public management and public services still lies with the government. But if it is considered as an exclusive process of involving the citizens then it can be understood as e-government. So based on this argument a framework is developed as shown in figure 1.

(ii) A framework is required to ensure that: (i) end users are satisfied with the services (ii) end-to-end systems and its components are conforming to the requirements of Request For Proposal (RFP)/Contract and (iii) solutions are in compliance with legal and regulatory requirements. Figure 1 and Table 1 shows the proposed framework, challenges and key functional quality measures establishing a quality management framework for effective public administration.

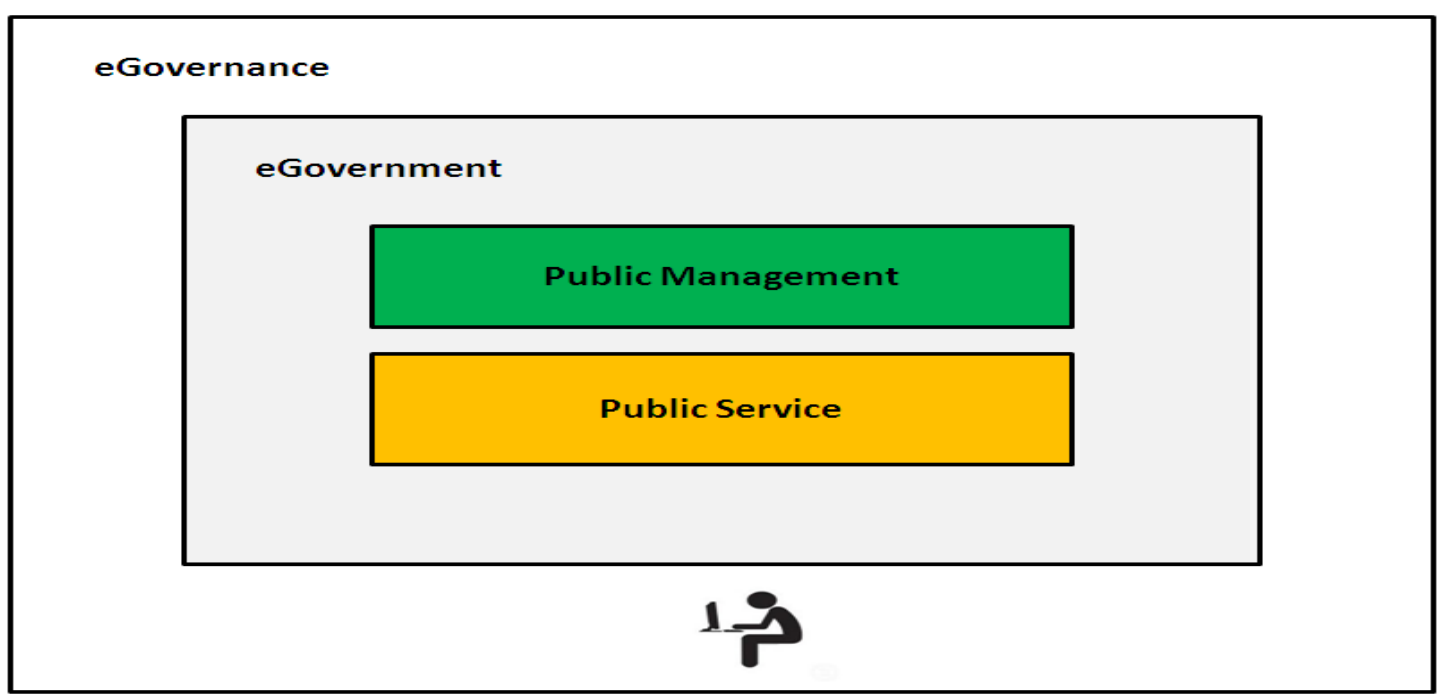

Figure 1. Framework for establishing quality management system in public administration 
At present, scientifically sound results of progress measurements are only available for some countries. But existing comparative benchmarking results across countries often lack a transparent description of the methods employed. So authors of this paper believed that a thorough theoretical ground work from the level of basic definitions can enable to progress towards setting bench marking policy and measurement variables for establishing quality management system in public administration.

Table 1. Challenges and Key functional measures in quality management system of effective public administration

\begin{tabular}{|c|c|c|c|}
\hline $\begin{array}{l}\text { Sl. } \\
\text { No. }\end{array}$ & System/Component & Challenges & $\begin{array}{l}\text { Key Functional Measures } \\
\text { of Quality Management }\end{array}$ \\
\hline 1. & e-Governance & $\begin{array}{l}\text { e-Government Challenges + } \\
\text { User Experience Challenges }\end{array}$ & $\begin{array}{l}\text { e-Government } \\
\text { Measures + } \\
\text { User Experience } \\
\text { Measures }\end{array}$ \\
\hline 2. & e-Government & $\begin{array}{l}\text { Public Management Challenges + } \\
\text { Public Service Challenges }\end{array}$ & $\begin{array}{l}\text { Public Management } \\
\text { Measures }+ \\
\text { Public Service } \\
\text { Measures }\end{array}$ \\
\hline 3. & $\begin{array}{l}\text { Public } \\
\text { Management }\end{array}$ & $\begin{array}{l}\text { Compliance with Legal and } \\
\text { Regulatory Requirements }\end{array}$ & $\begin{array}{l}\text { (i) Effectiveness, } \\
\text { (ii) Efficiency and (iii) } \\
\text { Equity }\end{array}$ \\
\hline 4. & Public Service & Conformance with RFP/Contract & $\begin{array}{l}\text { (i) Customer Satisfaction } \\
\text { (ii) Customer } \\
\text { Expectations } \\
\text { (iii) Electronic Service } \\
\text { Quality (iv) Self-Quality } \\
\text { Assessment Capability } \\
\text { (v) Dynamic } \\
\text { Benchmarking Capability } \\
\text { and (vi) Total Quality } \\
\text { Management. }\end{array}$ \\
\hline
\end{tabular}




\section{Macrothink}

Journal of Public Administration and Governance

ISSN 2161-7104

2012, Vol. 2, No. 4

\section{Adopting Lovelock and Wirt'z Service Quality Gap Model for e-Governance}

A review of worldwide efforts to revolutionise service relations on the basis of information and communication technologies (ICT) identifies still big gaps between ambitious goals and real progress in electronic service delivery (Aichhlozer 2001). To investigate the gaps in current e-governance research, gap analysis methodology is adopted. Though a number of perspectives on gaps can be given in terms of listing the categories (eGov RTD 2020), it is believed that the focusing on the service quality domain under service marketing perspective would give better results as research studies (Lovelock and Wright 2002; Brink and Berndt 2005) and others on service quality with service quality gap proved that it leads to better customer satisfaction. So the effort of current study is restricted to study the electronic service quality domain only.

It is believed that Service Quality Gap Model mentioned by Lovelock and Wirtz (2007) with Seven Service Quality Gaps can be adopted for adapting it to elicit e-governance based service quality dimensions and items in order to establish a total quality management based benchmark as well as for their measurement as shown in figure 1. It is an adapted and extended version from Zeithaml, Parasuraman and Berry (1990) and Zeithanl, Bitner and Gremler (2006).

The service quality equation mentioned in Lovelock and Wirtiz (2007) is given as follows:

Gap 7 = Gap1+Gap2+Gap3+Gap4+Gap5+Gap6

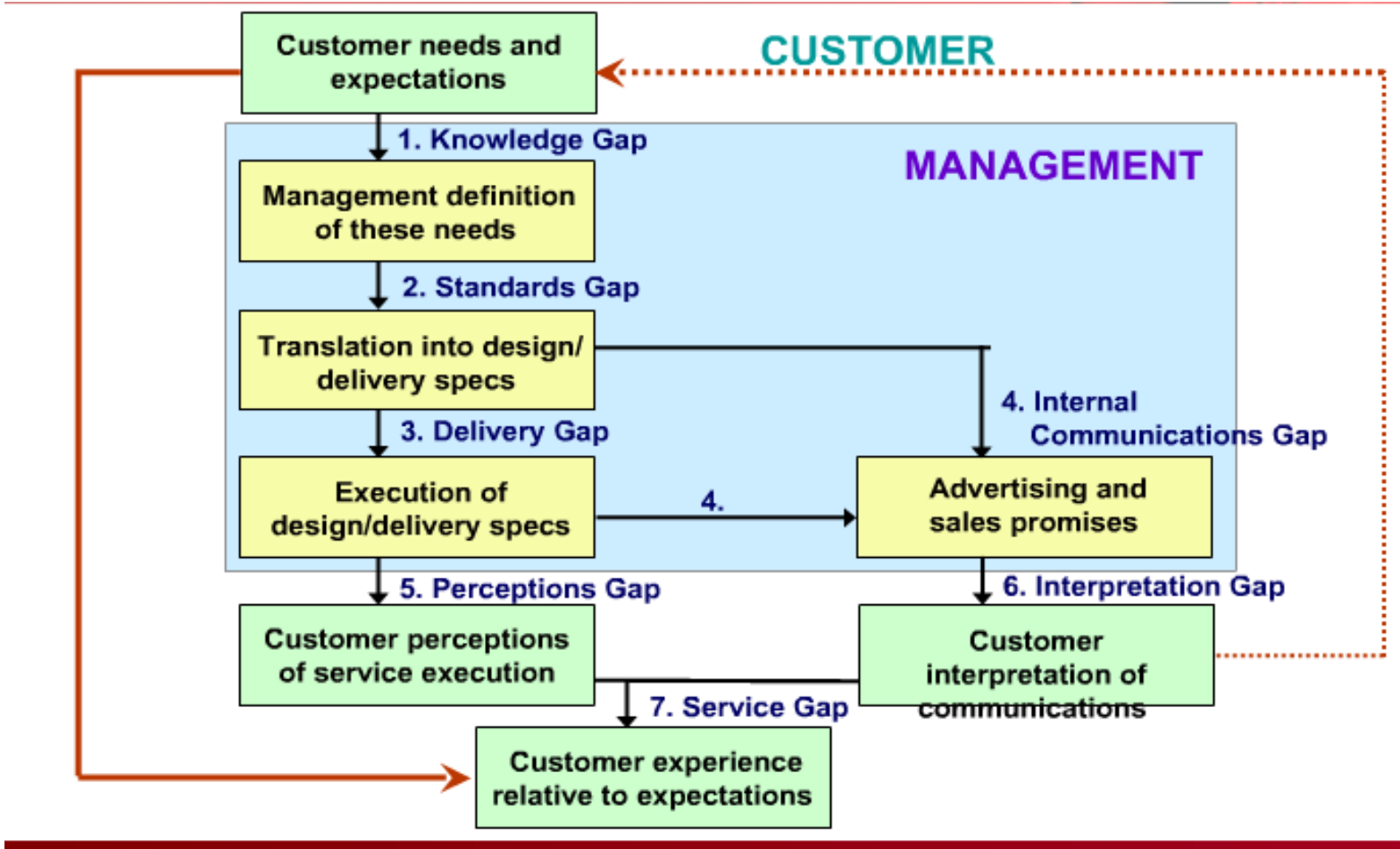

Figure 2. Lovelock and Wirtiz's Service Quality Gap Model (2007) 
Service Gap = Knowledge Gap + Standards Gap + Delivery Gap + Internal Communications Gap + Perceptions Gap + Interpretations Gap where:

1. Knowledge Gap: It is the gap between frontline staff and management in terms of customer expectations from market oriented information (Parasuraman et al., 2005). It requires turning this marketing oriented information into insights to perform actions (Lovelock and Wirtz 2007; AlSudairi and Vasista 2012).

2. Standards and Policy Gap: It is the gap between the service quality standards specification and actual reflections of those standards (Lovelock and Wirtz 2007) through the translation of web site design and delivery specifications.

3. Delivery Gap: It is the gap between the specified service standards and service performance (Lovelock and Wirtz 2007) through website (Lovelock and Wirtz 2007).

4. Internal Communication Gap: It is the gap between the frontline employees and customer expectations in terms of ensuring the communication settings (Lovelock and Wirtz 2007).

5. Perceptions Gap: It is the provision of evidence gap (Lovelock and Wirtz 2007) to the customer about the actual delivery of the service that customers can expect from the provider.

6. Interpretation Gap: It is the understanding gap between the customer and the service provider in terms of clarity and un-ambiguity (Lovelock and Wirtz 2007) in the service knowledge and interactions.

\section{Implications}

Implications of e-governance are slightly different for Arab countries like Saudi Arabia where public sector reforms or the New Public Management is internally driven. In some countries such as Turkey, there were no pressures to accept New Public Management Reforms and hence they might remain highly bureaucratised and extremely centralized (Saxena, 2005). Adopting e-governance as a form of New Public Management will have some positive and some negative implications. Positive implications include: Cost reduction and efficiency gain; quality of service delivery to business and customers; transparency, anti-corruption and accountability; network based reachability, improvement in the quality of decision making. Negative implications include: Weakness in huge initial investment on ICT infrastructure; Lack of knowledge and skills on e-governance programs; Lack of security and privacy of information; Lack of qualified personnel; Cultural Differences; Lack of legal, policy and regulations for e-usage; Getting support from Leaders and management; Lack of strategic plans, strategic partnership and collaborations; resistance to change to adopt e-systems (Nkwe, 2012)

\section{Conclusion}

Governments are considered organisations that are capable enough to quickly adopt new technologies to engage and serve constituents. Web sites act as tools for governments for communicating and providing services to their constituents. A key measure of good 
governance however is through the public sector that is in charge of delivering transparent and quality services. Worldwide it is believed that IT's role will be to predominantly improve quality of services in the public sector. The quality of public management and the quality of public services are becoming the two important quality considerations. E-governance can address number of principal aims of quality such as efficiency, effectiveness and equity with customer centricity in the process of establishing quality management system. So it is advised that governments in the process establishing quality management system in public administration should focus on working towards e-governance, which is citizen centric so as to create right organisational environment to achieve the effectiveness, efficiency and equity. E-governance is considered as the highest level of achieving service quality and customer satisfaction in quality management system as compared to just working on e-government.

\section{Acknowledgement}

Author acknowledges thanks to Deanship of Scientific Research, Dr. AlSudairi and Deanship of Library Affairs of King Saud University, Riyadh, Saudi Arabia for their indirect support in providing knowledge resources.

\section{References}

11th India Report, e-Governance: Conceptual Framework, Chapter-2, pp. 7-13. [Online] Available: http://arc.gov.in/11threp/ARC_11thReport_Ch2.pdf (May 05, 2012)

Agarwal, A., Shah Pragya \& Wadhwa, V. (2007). EGOSQ-Users' Assessment of e-Governance Online-Services: A Quality Measurement Instrumentation. [Online] Available: http://www.csi-sigegov.org/1/24_361.pdf (May, 05-2012).

Aichholzer, G. (2001). E-Government: the hard way from political agendas to service improvements.

[Online]

Available: http://www.itas.fzk.de/eng/e-society/preprints/egovernance/aichholzer_n.pdf (May 8, 2012).

AlSudairi, M. A. T. (2012). E-Service Quality Strategy: Achieving Customer Satisfaction in Online Banking, Journal of Theoretical and Applied Information Technology, Vol. 38, No. 1.

AlSudairi, M. A. T. \& Vasista T. G. K (2012). Model for Value Creation and Action Generation of an Electronic Enterprise in a Knowledge Based Economy, International Conference on Information Society (i-Society 2012), June 25-28, 2012, London, UK, IEEE Explore Proceedings.

Barker et al. (2008). Study on Industrial Policy and Services: Within the Framework Contracts of Sectoral Competitive Studies - ENTR/06/054, Final Report - Part I, European Commission Directorate-General Enterprise \& Industry, Rotterdam

eGov RTD 2020. Visions and Conceptions of European Citizens

Ehrenberg, R. \& Stupak, R. (1994). Total Quality Management: its relation to administrative theory and organistional behavior in the public sector, Public Administration Quarterly, Randallstown.

Ferreiera, M. P. \& Diniz, F. (2004). Total Quality Management and Public Administration: The case of Vila Real Town Hall, 44 th European Congress of the European Regional Science 
Association - Regions and Fiscal Federalism, University of Porto, Porto, Portugal, 25-29 August 2004, participants 664 and 665, paper 347.

IBM Governmental Programs (2006). Services and Global Competitiveness: Growth Opportunities for Developing Economies. [Online] Available: http://www.ibm.com/ibm/governmentalprograms/developingcountries.pdf, (May 02, 2012).

Infocomm Development Authority of Singapore. Singapore e-Government Journey, Ps. $1-12$ [Online]

Available: http://www.pacsa.gov.la/accsm/resources/Singapore/Country\%20Report\%20-\%20Singapore $\% 20$ eGovernment.pdf, (May 5, 2012).

Kanji, G. K. (2002), Measuring Business Excellence, Rout ledge Advances in Management and Business Studies, Routledge, London, UK.

Loffler (2001). Defining and Measuring Quality in Public Administration, BBS Teaching and Research Review, Issue 5.

Lovelock, C. \& Wirtz, J. (2007). Services Marketing: People, Technology, Strategy. (6th Edition). USA: Pearson/Prentice Hall, USA.

Misuraca, G. (2007). E-Governance in Africa, from Theory to Action: A Handbook on ICTs for Local Governance, First Edition, Africa World Press and International Development Research Centre.

Moura e Sa, P. (2009). E-Government implementation and total quality management adoption: An empirical study in the Portuguese Municipalities. Working Paper.

Moura e Sá, P. (2011). eGovernment Implementation and TQM Adoption: an Empirical Study in the Portuguese Municipalities. Electronic Journal of e-Government. Vol. 9 Iss.1, pp. 58 67.

Nabitz, U., Klazinga, N. \& Walburg, J. (2000). The EFQM excellence model: European and Dutch experiences with the EFQM approach in health care, International Journal for Quality in Health Care, Vol. 12, No. 3, pp. 191-201.

Naz, R. (2009). E-Governance for Improved Public Service Delivery in Fiji, Journal of Service Science and Management, Vol. 3, pp. 190-203.

Nkwe, N. (2012). E-Government: Challenges and Opportunities in Botswana. International Journal of Humanities and Social Sciences, Vol. 2, No. 17.

OECD-STI (2000). The Service Economy, Service Technology Industry: Business and Industry Policy Forum Series, OECD Publications, France, [Online] Available: http://www.oecd.org/dataoecd/10/33/2090561.pdf (May 02 2012).

OECD and Dubai School of Government (2007). Good Governance for development in Arab Countries Initiative: Measuring and Evaluating E-Government in Arab Countries, High level Seminar on Measuring and Evaluating E-Government and 3rd Meeting of working group 2 on E-Government and Administrative Simplification, 12-13 March 2007, Dubai. [Online] Available: http://www.oecd.org/dataoecd/55/16/39856235.pdf (May 05, 2012)

Raharjo, H., Brombacher, A. C., Chai, K. H. and Bergman, B. (2008). Dynamic Benchmarking Methodology for Quality Function Deployment, IEEE. 
Rowley, J. (2011). E-Government stakeholders-Who are they and what do they want?, International Journal of Information Management, vol. 31, Iss. 1, pp. 53-62.

Saxena,K. B. C. (2005). Towards Excellence in E-Governance. Working Paper No. 2005-1. Centre for Excellence in Information Management, MDI, Gurugaon, UNPAN045361. [Online] Available: http://unpan1.un.org/intradoc/groups/public/documents/apcity/unpan045361.pdf (December 10, 2012)

Scott, J. K. (2005). Assessing the quality of municipal government web sites, State and Local Government Review, Vo. 37, No. 2, pp. 151-165

Schacter, M. (2008). How good is your government? Assessing the quality of Public Management, Mark Schacter Consulting, Ottawa, Ontario, Canada [Online] Available: http://www.schacterconsulting.com/documents/howgood.pdf (May 2, 2012)

West, J., Berman, E. \& Milakovich, M. (1993), Implementing TQM in local government: the leadership challenge, Public Productivity \& Management Review, San Francisco.

Wiki-Service Quality [Online] Available: http://en.wikipedia.org/wiki/Service_quality (May 02, 2012.

Zeithaml, V. A. Parasuraman, A. \& Berry, L. L. (1990). Delivering service quality: Balancing customer perceptions and expectations. New York: The Free Press;

Zeithaml, V. A., Bitner, M. J., \& Gremler, D. (2006). Services marketing: Integrating customer focus across the firm, 4th Edition, New York: McGraw-Hill.

Zurga, G. (2008). Quality Management in Public Administration of the EU Member States Comparative Analysis, Ministry of Public Administration, Republic of Slovenia, European Public Administration Network.

\section{Copyright Disclaimer}

Copyright reserved by the author(s).

This article is an open-access article distributed under the terms and conditions of the Creative Commons Attribution license (http://creativecommons.org/licenses/by/3.0/). 